\title{
Protective effect of Xuebijing injection on paraquat-induced pulmonary injury via down-regulating the expression of p38 MAPK in rats
}

Ming-wei Liu*, Mei-xian Su², Wei Zhang ${ }^{1}$, Yan-qiong Wang ${ }^{3}$, Mei Chen ${ }^{4}$, Li Wang ${ }^{1}$ and Chuan-yun Qian ${ }^{1}$

\begin{abstract}
Background: Exposure to paraquat results in acute lung injury. A systemic inflammatory response has been widely established as a contributor to paraquat-induced acute lung injury. Recent studies have reported that consumption of Xuebijing prevents inflammatory response-induced diseases. This study investigated whether consumption of Xuebijing protected rats against paraquat-induced acute lung injury.
\end{abstract}

Methods: Adult male Sprague Dawley rats were randomly divided into four groups: control group; paraquat group; paraquat + Xuebijing group; and paraquat + dexamethasone group. Rats in the paraquat, paraquat + Xuebijing and paraquat + dexamethasone groups were intraperitoneally injected with paraquat $(30 \mathrm{mg} / \mathrm{kg})$ or administered paraquat and Xuebijing at $8 \mathrm{~mL} / \mathrm{kg}$ or dexamethasone at $5 \mathrm{mg} / \mathrm{kg}$, respectively, via an injection into the tail vein. Lung p38 MAPK, NF-KB65, IkB, p-IKB-a, HIF-1a, Nrf2 and TGF- $\beta 1$ expression were essayed using western blotting. IL-6, TNF- $\alpha$, IL-1 $\beta$, IL-10, TGF- $\beta 1$ and PIIIP were measured using ELISA. ROS, oxidised glutathione and glutathione activity were measured.

Results: After inducing acute lung injury with paraquat for $24 \mathrm{~h}$, Xuebijing was observed to block lung p-p38 MAPK, NF-KB65, HIF-1a, p-IKB- $a$ and TGF- $\beta 1$ expression, and increased Nrf2 and IkB expression. The numbers of neutrophils and lymphocytes and total number of cells were significantly lower in the Xuebijing group compared with the control group. IL-6, TNF-a, IL-1 $\beta$, TGF- $\beta 1$ and PIIIP levels were significantly decreased in the Xuebijing group. ROS and oxidised glutathione activity were markedly inhibited by Xuebijing. Histological evaluation showed attenuation of the effects of Xuebijing on paraquat-induced lung injury. Compared with the paraquat + dexamethasone group, the Xuebijing + paraquat group showed no significant differences.

Conclusions: Inhibiting the expression of p38 MAPK and NF-KB65 was crucial for the protective effects of Xuebijing on paraquat-induced acute lung injury. The findings suggest that Xuebijing could effectively ameliorate paraquat-induced acute lung injury in rats. Xuebijing was as effective as dexamethasone at improving paraquat-induced lung injury by regulating lung inflammation, lung function and oxidative stress responses.

Keywords: Xuebijing, Paraquat, Acute lung injury, p38 MAPK, NF-kB65, Rat

\footnotetext{
* Correspondence: Lmw2004210@163.com

1 Department of Emergency, The First Hospital Affiliated To Kunming Medical University, 295 Xichang Road, Wu Hua District, Kunming 650032, China

Full list of author information is available at the end of the article
} 


\section{Background}

Paraquat (1,1-dimethyl-4,4-bipyridilium dichloride) is a widely used contact and nonselective quaternary nitrogen herbicide. Since its first introduction into agricultural use in 1962, it has caused thousands of human deaths, either by accidental or voluntary ingestion. The toxicity of paraquat is based on its induction of redox cycling, which results in oxidative stress-related cell death and inflammation. Because of its selective accumulation in the lungs, it causes severe lung injury, manifesting in oedema, haemorrhage, interstitial inflammation, and progressive fibrosis [1,2]. Many studies have suggested that the mechanisms of paraquat-induced lung injury are mainly associated with the systemic inflammatory response $[3,4]$. Histologically, acute lung injury (ALI) in humans is characterised by a severe acute inflammatory response in the lungs and neutrophilic alveolitis [5]. The physiological hallmark of acute respiratory distress syndrome is disruption of the alveolarcapillary membrane barrier, which results in the development of noncardiogenic pulmonary oedema in which a proteinaceous exudate floods the alveolar spaces, impairs gas exchange and precipitates respiratory failure [6,7]. ALI can result in persistent respiratory failure and prolonged dependence on mechanical ventilation, thereby increasing susceptibility to multiorgan dysfunction and mortality [8]. Despite extensive investigation aimed at early diagnostic and pathogenic factors of ALI, current management is mainly supportive because specific therapies have not been identified [9-11]. Animal models focused on ALI pathogenesis have yielded insights into mechanisms that initiate injury; however, little is known about the potential determinants of treatment $[12,13]$. Thus, new strategies are still required to achieve effective treatment of ALI, which might ultimately aid in clinical therapy for ALI patients.

Numerous basic and clinical studies have demonstrated that overexpression of TNF- $\alpha$ and IL- $1 ß$ can induce ALI [14]. In addition, cytokine production is associated with activation of the p38-mitogen activated protein kinase (p38 MAPK) pathway [15]. Cytokine production is also regulated by p38 MAPK. Inactivated p38 MAPK is normally located in the cytoplasm and is translocated into nuclei following activation, where it activates the activator protein-1 by phosphorylating myocyte-specific enhancer factor-2C, activating transcription factor-2, and $\mathrm{E}$ twentysix-like transcription factor-1, thereby regulating the production of TNF- $\alpha$ and IL-1ß.

Xuebijing is a Chinese herbal compound preparation mainly consisting of Chuanxiong (Rhizoma Chuanxiong), Chishao (Radix Paeoniae Rubra), Danshen (Radix Salviae Miltiorrhiae), and Honghua (Flos Carthami). Xuebijing can clear heat, cool blood, promote gas and blood circulation, remove toxic substances, and relieve pain [16]. Furthermore, Xuebijing has been used to treat systemic inflammatory response syndrome, pyemia, and multiple organ dysfunction syndrome [17].

In the present study, we hypothesised that Xuebijing could reduce inflammatory-induced lung injury following paraquat poisoning. We examined the expression of cytokines and p38 MAPK in the lung following treatment with Xuebijing in a rat model of paraquat-induced lung injury.

\section{Methods}

Drugs

Xuebijing injections were obtained from Tianjin Chase Sun Pharmaceutical Co., Ltd. (No. Z20040033; Tianjin, China), and consisted of Chuanxiong, Chishao, Danshen and Honghua. Chuanxiong, Chishao, Danshen and Honghua were obtained from Prof. Li Shixia of Central South University and deposited at the Pharmacy Centre.

\section{Reagents}

Rabbit anti-mouse NF- $\mathrm{B} 65$ and p38 MAPK antibodies were obtained from Santa Cruz Biotechnology (Santa Cruz, CA, USA). Mouse TNF- $\alpha$, IL- $1 \beta$ and IL-6 ELISA kits were purchased from Quantikine, R\&D Systems (Minneapolis, MN, USA). The Griess reagent nitric oxide assay kit was purchased from Beyotime Biotech (Jiangsu, China). The mouse IL-10 ELISA kit was obtained from Bender MedSystems (Vienna, Austria). Paraquat was purchased from Sigma.

\section{Main instruments}

An Olympus inverted microscope (Olympus, Tokyo, Japan), low-temperature refrigerated centrifuge (Eppendorf, Germany), clean bench (Suzhou Purification Equipment Co., Ltd.), continuous wavelength microplate reader (BioRad Laboratories Inc., Hercules, CA, USA), electronic balance (Sartorius Instrument \& System Engineering Co., Ltd, Beijing, China), haemocytometer (Qiujing Biochemical Instrument Factory, Shanghai, China), AE31 inverted phase contrast microscope (Motic), and electric homogeniser (Kemi Instrument \& Meter Co., Ltd. Zhenjiang, China) were used in this study.

\section{Experimental animals}

Male Sprague Dawley rats were purchased from Kunming Medical University Laboratory Animal Center (Kunming, China). All rats were housed at the Kunming Medical University Animal Care Facility and were maintained in pathogen-free conditions. Rats were 8-9 weeks of age at the initiation of the experiment and were maintained on standard laboratory chow and water was provided ad libitum. All experiments were approved and performed according to the guidelines of the Animal Care Committee of Kunming Medical University. 


\section{Preparation of Xuebijing from Chuanxiong, Chishao, Danshen and Honghua}

We prepared Xuebijing as previously described in the literature [18]. The appropriate amount of dried Chuanxiong, Chishao, Danshen and Honghua was weighed and twice backflow extractions were performed using chloroform: methanol $(2: 1)$ at $50^{\circ} \mathrm{C}$ in a water bath for $2 \mathrm{~h}$ at each time point. The liquid was discarded, and ultrasonic extraction with the residue with $80 \%$ ethanol was performed three times (20 min each) and filtered. The filtrate was discarded for ultrasonic extraction with water three times $(20 \mathrm{~min}$ each) and filtered. To lower the temperature of the concentration of the combined filtrate, $95 \%$ ethanol was added, and the solution was allowed to stand at a low temperature for $24 \mathrm{~h}$. To obtain Xuebijing, several washes were performed and the solids were extracted and filtered with absolute ethanol and acetone prior to vacuum drying.

\section{HPLC determination of Xuebijing}

Analyses were performed using a liquid chromatography system (Waters, Milford, MA, USA) with 515 pumps, equipped with an online degasser, a Waters pump control module, an autosampler 717, a Waters 2996 photodiode array detector, and Waters Empower software. Separation was performed using a Supelcosil LC-8-DB column $(250 \times 4.6 \mathrm{~mm}$ i.d.; $5 \mu \mathrm{m}$ pore size $)$ with a guard column $(40 \times 4.6 \mathrm{~mm}$ i.d. $)$ packed with the same material. The column was maintained at $25^{\circ} \mathrm{C}$ throughout the analysis, and detection was performed at $254 \mathrm{~nm}$. Elution was performed at a flow rate of $0.8 \mathrm{~mL} / \mathrm{min}$ with water as solvent $A$ and methanol as solvent $B$. In addition, an isocratic elution from $0-10$ min with $90 \%$ of A followed by a gradient elution from 10-15 min with $90-85 \%$ of A, 15-30 min with $85-70 \%$ of A, 30-37 min with 70-90\% of A, and isocratic from $37-45$ min with $90 \%$ of A was performed. A stock solution of Xuebijing $(1 \mathrm{mg} / \mathrm{mL})$ was prepared in methanol and analysis was performed under the same working conditions. Each analysis was repeated three times, and the respective retention times were averaged. Peak identification in HPLC analysis was performed by comparing the retention time with the reference standard. Quantification of the compounds was achieved using the calibration plot of the standard solution.

The concentrations for the standard used for the calibration curve ranged from $1.0 \mu \mathrm{g}$ to $5.0 \mu \mathrm{g}$ for Xuebijing. Each run was repeated three times.

Chromatography was performed at room temperature with a flow rate of $1.0 \mathrm{~mL} / \mathrm{min}$, and $10 \mu \mathrm{L}$ of volume was analysed. Analysis (Figure 1) showed that $1 \mathrm{~L}$ of the Xuebijing injection contained $38.61 \mathrm{mg}$ uridine, 11.98 mg gallic acid, 27.04 mg guanosine, $48.33 \mathrm{mg}$ danshensu sodium, $7.15 \mathrm{mg}$ paeoniflorin, $19.6 \mathrm{mg}$ protocatechuic

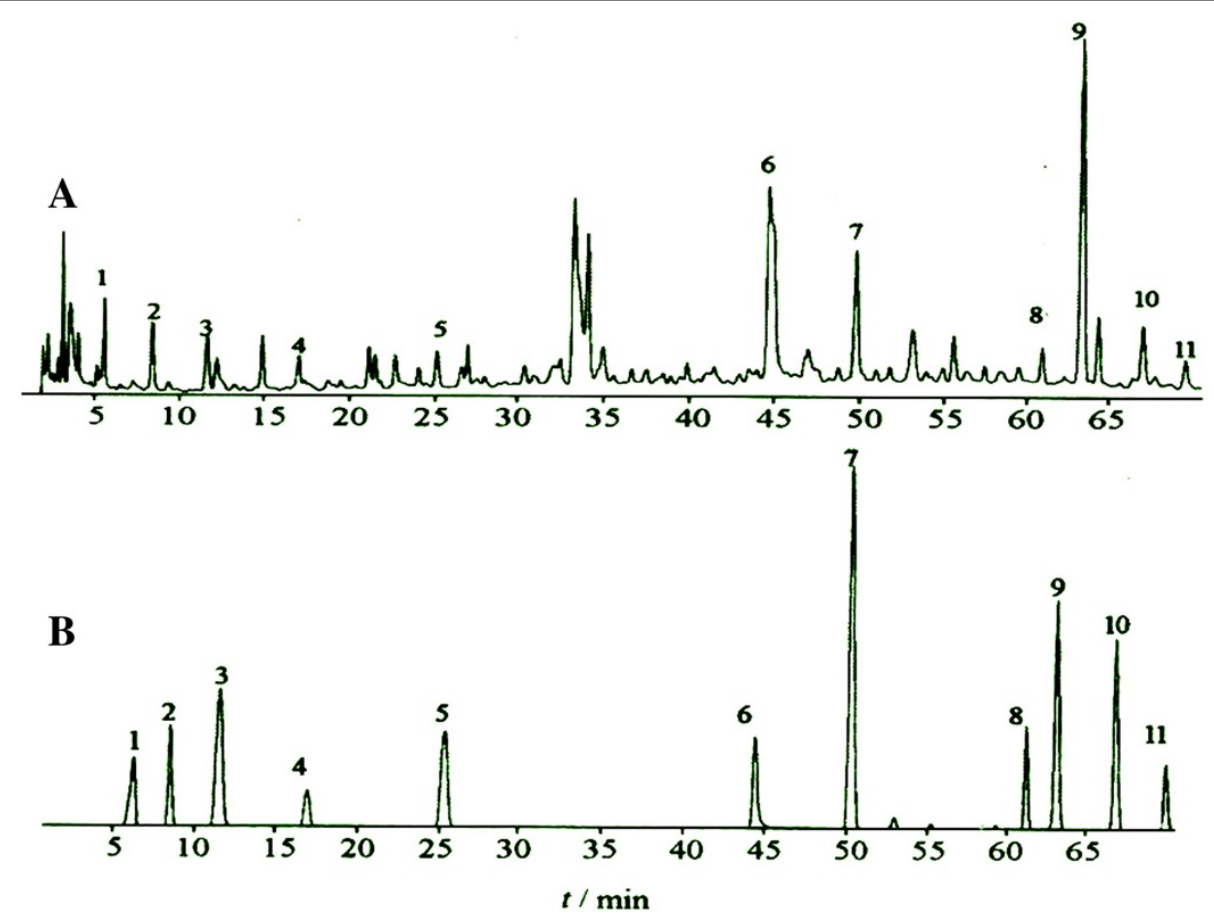

Figure 1 Chromatogram of the chemical reference substances and sample. A: Chromatogram of the chemical reference substances. B: Chromatogram showing the following samples: 1, uridine; 2, gallic acid; 3, guanosine; 4, danshensu sodium; 5, paeoniflorin; 6, protocatechuic aldehyde; 7, ferulic acid; 8, salvianolic acid B; 9, safflor yellow A; 10, senkyunolide; and 11, senkyunolide. 
aldehyde, $37.40 \mathrm{mg}$ ferulic acid, $29.82 \mathrm{mg}$ salvianolic acid B, $48.66 \mathrm{mg}$ safflor yellow A, $53.15 \mathrm{mg}$ senkyunolide I, and $19.29 \mathrm{mg}$ senkyunolide.

\section{Animal groupings and drug administration}

Briefly, rats were randomly assigned into one of four groups: the saline control group, paraquat group, Xuebijing + paraquat group and dexamethasone + paraquat group $(n=20$ for each group). From previous experiments and reports [2,16], ALI was induced by an intraperitoneal paraquat injection $(30 \mathrm{mg} / \mathrm{kg}$ ) and left untreated for $1 \mathrm{~h}$. Subsequently, rats were given either Xuebijing $8 \mathrm{~mL} / \mathrm{kg}$, dexamethasone $5 \mathrm{mg} / \mathrm{kg}$ or $300 \mu \mathrm{l}$ of normal saline via injection into the tail vein. Three to five rats from each group were anaesthetised and killed at 48-h post-injection of paraquat for cytokine concentration measurements, assessment of lung injury, and histology.

\section{Collection of bronchoalveolar lavage fluid (BALF) and tissue samples}

Rats were euthanised and their thoraxes were opened via a midline thoracotomy. Three millilitres of blood was collected from the heart and centrifuged at $2000 \times g$ at $4^{\circ} \mathrm{C}$ for $10 \mathrm{~min}$. The serum was collected and stored at $-80^{\circ} \mathrm{C}$ until further analysis. After euthanising the rats, the trachea was isolated and the right bronchial tube was ligated. BALF was obtained by placing a 20 -gauge catheter into the trachea through which $3 \mathrm{~mL}$ of cold PBS was flushed back and forth three times. BALF was centrifuged at $3000 \times g$ for $20 \mathrm{~min}$ at $4^{\circ} \mathrm{C}$. The resulting cell pellet was used to determine the total cell count using a counter (Beckman Coulter). A cell smear was made using Wright-Giemsa staining to confirm the percentage of inflammatory cells. The protein concentration of the cell-free BALF from all groups was measured using a Bio-Rad protein assay kit and was used as an indication of endothelial and epithelial permeability. The right middle lung lobes were stored in liquid nitrogen at $-80^{\circ} \mathrm{C}$ until analysis. The right upper lobes were used to quantify the magnitude of pulmonary oedema. The right lower lobes were used for histological evaluation.

\section{Western blotting}

Lung tissues were homogenised in lysis buffer containing protease inhibitors, and protein concentrations were determined using Bradford reagent (Bio-Rad). Samples were loaded onto an SDS-PAGE gel. After electrophoresis at $120 \mathrm{~V}$ for $90 \mathrm{~min}$, the separated proteins were transferred onto polyvinylidene difluoride membranes (GE Healthcare, Little Chalfont, United Kingdom) by the wet transfer method (250 mA, $90 \mathrm{~min}$ ). Nonspecific sites were blocked with $5 \%$ non-fat dry milk in Tris-buffered saline with Tween 20 (25 mM Tris, pH 7.5, $150 \mathrm{mM}$ $\mathrm{NaCl}, 0.1 \%$ Tween 20) for $1 \mathrm{~h}$, and the blots were incubated overnight at $4^{\circ} \mathrm{C}$ with anti-TGF- $\beta 1$ antibody (Sigma-Aldrich), anti-p38 MAPK antibody (Cell Signaling Technology Inc.), anti-p-p38 MAPK antibody (R\&D Systems, Inc.), anti-NF-kB65 antibody (Cell Signaling Technology Inc.), anti-IkB antibody (Cell Signaling Technology Inc.), anti-p-IkB- $\alpha$ antibody (Cell Signaling Technology Inc.), anti-HIF- $1 \alpha$ antibody (Cell Signaling Technology Inc.), and anti-Nrf2 antibody (Cell Signaling Technology Inc.). Anti-rabbit or anti-mouse horseradish peroxidase conjugated-IgG antibodies were used to detect binding of the antibodies. The membranes were stripped and reblotted using an anti-actin antibody (Sigma-Aldrich) to normalise the loading of protein in each lane. The binding of specific antibodies was visualised by exposing the membranes to photographic film after treatment with enhanced chemiluminescence system reagents (GE Healthcare).

\section{Determination of the activation of NF-KB65 using immunohistochemistry}

Immunostaining was performed on lung sections after antigen retrieval using Retrievagen A (Zymed, South San Francisco, CA, USA) at $100^{\circ} \mathrm{C}$ for $20 \mathrm{~min}$, and endogenous peroxidases were quenched with $3 \% \mathrm{H}_{2} \mathrm{O}_{2}$. Sections were blocked with $2 \%$ BSA in PBS followed by staining with primary anti-NF-kB65 at room temperature for $1 \mathrm{~h}$. Sections were washed, and after application of the secondary antibody (R\&D Systems), tissues were developed using Vectastain ABC (Vector Labs, Burlingame, CA, USA) and 3,3'-diaminobenzidine (Vector Labs). Using Image Pro Plus image analysis software (Media Cybernetics, Bethesda, MD, USA), NF-кB65-positive expression in lung tissue was determined and expressed as positive units.

\section{Determination of cytokines, TGF- $\beta 1$ and PIIIP in serum using ELISA}

Nalgene Nunc MaxiSorp plates were coated with primary antibodies for either IL-6, TNF- $\alpha$, IL-1 $\beta$, IL-10, TGF- $\beta 1$ or PIIIP (R\&D Systems) for $1 \mathrm{~h}$ at room temperature and washed with PBS and 0.5\% Tween 20. After blocking with casein, the samples were added to plates for $1 \mathrm{~h}$ at room temperature. Following washing, biotinylated secondary antibodies were applied for $1 \mathrm{~h}$ followed by streptavidinHRP conjugate (Jackson ImmunoResearch, West Grove, PA, USA) diluted at 1:20,000. The reaction was developed with $0.01 \%$ tetramethylbenzidine dissolved in dimethyl sulfoxide and $0.5 \%$ hydrogen peroxide and measured using endpoint spectrometry.

\section{Determination of the total cell number and inflammatory cells}

Using a previously described method [19], bronchoalveolar lavage was performed by instilling $0.9 \% \mathrm{NaCl}$ containing $0.6 \mathrm{mmol} / \mathrm{L}$ EDTA in two separate $0.5 \mathrm{~mL}$ 
aliquots. The fluid was recovered by gentle suction and placed on ice for immediate processing. An aliquot of BALF was processed immediately for total and differential cell counts. The remainder of the lavage fluid was centrifuged and the supernatant was removed aseptically and stored in individual aliquots at $-70^{\circ} \mathrm{C}$. Total cell counts in BALF were determined using a haemocytometer. The number of inflammatory cells was calculated as the percentage of inflammatory cells multiplied by the total number of cells in the BALF sample. All analyses were performed in a blind fashion.

\section{Albumin concentration of BALF}

The albumin content of the bronchoalveolar lavage supernatant was assessed using an ELISA kit for albumin (E91028Mu; Uscn Life Science Inc., Wuhan, China). Measurement of the absorbance at $450 / 540 \mathrm{~nm}$ was performed using a microplate reader (Infinite 200; Tecan Group, Zürich, Switzerland).

\section{Measurement of pulmonary oedema}

Total lung water content, a quantification of pulmonary oedema, was measured as previously described [20]. The left lung was isolated for determination of total lung water content. The lung was weighed using an automatic electric balance (Sartorius, Goettingen, Germany) and was placed in an oven at $80^{\circ} \mathrm{C}$ for $48 \mathrm{~h}$ before being weighed again to obtain its dry weight. Total lung water content was calculated as follows: total lung water content $=$ (wet lung weigh - dry lung weight $) /($ dry lung weight).

\section{Measurement of intracellular ROS}

ROS was measured using a previously described method [21]. BAL cells were washed with PBS. To measure intracellular ROS, cells were incubated for $10 \mathrm{~min}$ at room temperature with PBS containing $3.3 \mu \mathrm{M} \mathrm{2}$ ', $7^{\prime}$-dichlorofluorescein (DCF) diacetate (Molecular Probes, Eugene, OR, USA) to label intracellular ROS. We performed fluorescence-activated cell sorting analysis with DCF stained cells $(1 \times 104$ cells $)$ in BALF to measure ROS levels using a FACSCalibur (BD Biosciences, San Jose, CA, USA). The data were analysed using CellQuest Pro (BD Biosciences).

\section{Measurement of glutathione and oxidised glutathione in lung tissues}

Lung tissues were homogenised with $10 \mathrm{~mL}$ of ice-cold lysis buffer (50 mM phosphate buffer containing $1 \mathrm{mM}$ EDTA) per gram of tissue. After centrifugation at $10,000 \times g$ for $15 \mathrm{~min}$ at $4^{\circ} \mathrm{C}$, the supernatant was removed, deproteinated, and stored at $-20^{\circ} \mathrm{C}$ until further analyses. Total glutathione and oxidised glutathione levels were determined using a glutathione assay kit (Cayman
Chemical Co., Ann Arbor, MI, USA), according to the manufacturer's protocol.

\section{Determination of the total lung collagen content}

The total lung collagen content was determined using the Sircol Collagen Assay Kit (Biocolor Ltd., Belfast, Northern Ireland) according to the manufacturer's protocol.

\section{Lung histopathology}

Lung tissues were fixed in 4\% paraformaldehyde, embedded in paraffin, and cut into $5-\mu \mathrm{m}$ thick sections. Sections were stained with hematoxylin and eosin, and images were taken with a Nikon Eclipse E800 microscope $(200 \times)$. For the lung injury score, images were evaluated by an investigator who was blinded to the identity of the slides, as previously described [6]. Briefly, the extent of the pathological lesions was graded from 0 to 3 as shown in Table 1. The score for each animal was calculated by dividing the total score for the number of sections observed.

\section{Statistical analysis}

Data are expressed as mean \pm SEM, unless otherwise indicated. Data were analysed using ANOVA followed by the Newman-Keuls comparison. For two-group comparisons, an unpaired Student's $t$-test was used (GraphPad Software, San Diego, CA, USA). A P-value $<0.05$ was considered statistically significant.

\section{Results}

\section{Histology}

To determine the effect of Xuebijing on histological lung injury, histopathological analysis was performed on sections stained with haematoxylin and eosin. As show the Figure 2, Histological analyses of lungs following paraquat exposure revealed that the capillaries in the lung tissue expanded and became congested by the significant increase in neutrophils. Additionally, lung septa thickened and did not show any improvement $48 \mathrm{~h}$ later, and lung injury score was markedly increased. Xuebijing + paraquat group rats also displayed moderate injury, but the severity was significantly ameliorated and lung injury score significantly decreased compared with the paraquat group, and compared with the dexamethasone + paraquat group, there were no significant differences.

\section{Xuebijing inhibited the expression of p-p38 MAPK, NF-kB65, p-IkB- $\alpha$, HIF-1 $\alpha$ and TGF- $\beta 1$, and up-regulated IkB and Nrf2 in paraquat-induced lung tissue}

To assess the potential role of Xuebijing in paraquatinduced ALI, we determined the levels of p-p38 MAPK, NF-kB65, IkB, p-IкB- $\alpha$, HIF- $1 \alpha$, Nrf2 and TGF- $\beta 1$ proteins in lung tissue of paraquat-induced ALI rats using western blotting at $24 \mathrm{~h}$ after paraquat challenge (Figure 3 ). 
Table 1 Acute lung injury pathology scoring criteria

\begin{tabular}{lllll}
\hline Score & Alveolar septa & Alveolar haemorrhage & Intra-alveolar fibrin & Intra-alveolar infiltrations per field \\
\hline 0 & All are thin and delicate & No haemorrhage & No intra-alveolar fibrin & Less than 5 intra-alveolar cells \\
1 & $\begin{array}{l}\text { Congested alveolar septa in } \\
\text { less than } 1 / 3 \text { of the field }\end{array}$ & $\begin{array}{l}\text { Erythrocytes per alveolus in } \\
1 \text { to } 5 \text { alveoli }\end{array}$ & $\begin{array}{l}\text { Fibrin strands in less than } 1 / 3 \\
\text { of the field }\end{array}$ & 5 to 10 intra-alveolar cells \\
2 & $\begin{array}{llll}\text { Congested alveolar septa in } \\
1 / 3 \text { to } 2 / 3 \text { of the field }\end{array}$ & $\begin{array}{l}\text { At least } 5 \text { erythrocytes per alveolus } \\
\text { in } 5 \text { to } 10 \text { alveoli }\end{array}$ & $\begin{array}{l}\text { Fibrin strands in } 1 / 3 \text { to } 2 / 3 \text { of } \\
\text { the field }\end{array}$ & 10 to 20 intra-alveolar cells \\
3 & $\begin{array}{llll}\text { Congested alveolar septa in } \\
\text { greater than } 2 / 3 \text { of the field }\end{array}$ & $\begin{array}{l}\text { At least } 5 \text { erythrocytes per alveolus } \\
\text { in more than } 10 \text { alveoli }\end{array}$ & $\begin{array}{l}\text { Fibrin strands in greater than } \\
2 / 3 \text { of the field }\end{array}$ & More than 20 intra-alveolar cells \\
& & &
\end{tabular}

At $48 \mathrm{~h}$ after paraquat administration, lung p-p38 MAPK, NF-кB65, HIF- $1 \alpha$, p-IкB- $\alpha$ and TGF- $\beta 1$ expression showed significant increases, and Nrf2 and IkB expression was significantly reduced. However, Xuebijing significantly attenuated the expression of p-p38 MAPK, NF-кB65, HIF- $1 \alpha, p-\mathrm{I} \kappa \mathrm{B}-\alpha$ and TGF- $\beta 1$, and up-regulated Nrf2 and IkB expression, and compared with the dexamethasone + paraquat group, there were no significant differences.

\section{Xuebijing inhibited the activation of NF-KB65 in paraquat-induced lung tissue}

Lung activation of NF-kB65 was very weak at $48 \mathrm{~h}$ in the control group (Figure 4). However, NF-kB65 expression was markedly increased in the paraquat and Xuebijing + paraquat groups. At $48 \mathrm{~h}$ after Xuebijing administration, activation of NF-kB65 was markedly inhibited in the Xuebijing + paraquat group, and compared with the dexamethasone + paraquat group, there were no significant differences.

\section{Xuebijing treatment attenuated systemic inflammation}

Serum was collected at $48 \mathrm{~h}$ to evaluate the levels of TNF- $\alpha$, IL-1 $\beta$, IL-6, and IL-10. As shown the Figure 5, paraquat caused a significant acute systemic inflammatory response as demonstrated by the increased serum concentrations of the pro-inflammatory mediators TNF- $\alpha$, IL- $1 \beta$, and IL-6. The presence of Xuebijing reduced the increase
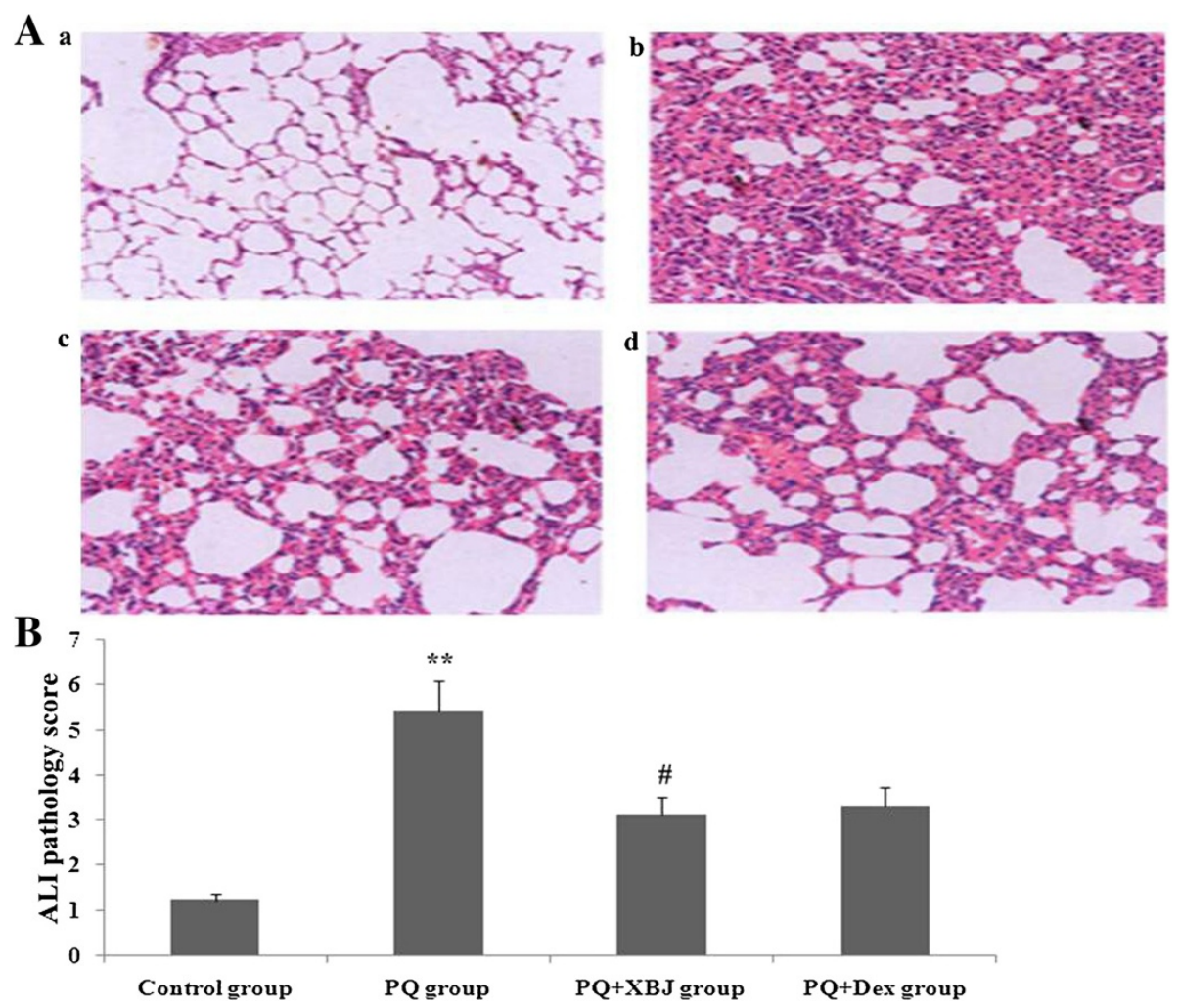

Figure 2 Changes in lung pathology and lung injury score. A: Representative lung pathological graphs (a: control group, b: paraquat group, c: Xuebijing + paraquat group, d: dexamethasone + paraquat group). B: Statistical analysis of lung injury score. Data are expressed as mean \pm SEM. ${ }^{* *} P<0.01$ compared with control group; ${ }^{*} P<0.05$ compared with paraquat group; $P>0.05$ Xuebijing + paraquat group compared with dexamethasone + paraquat group. 


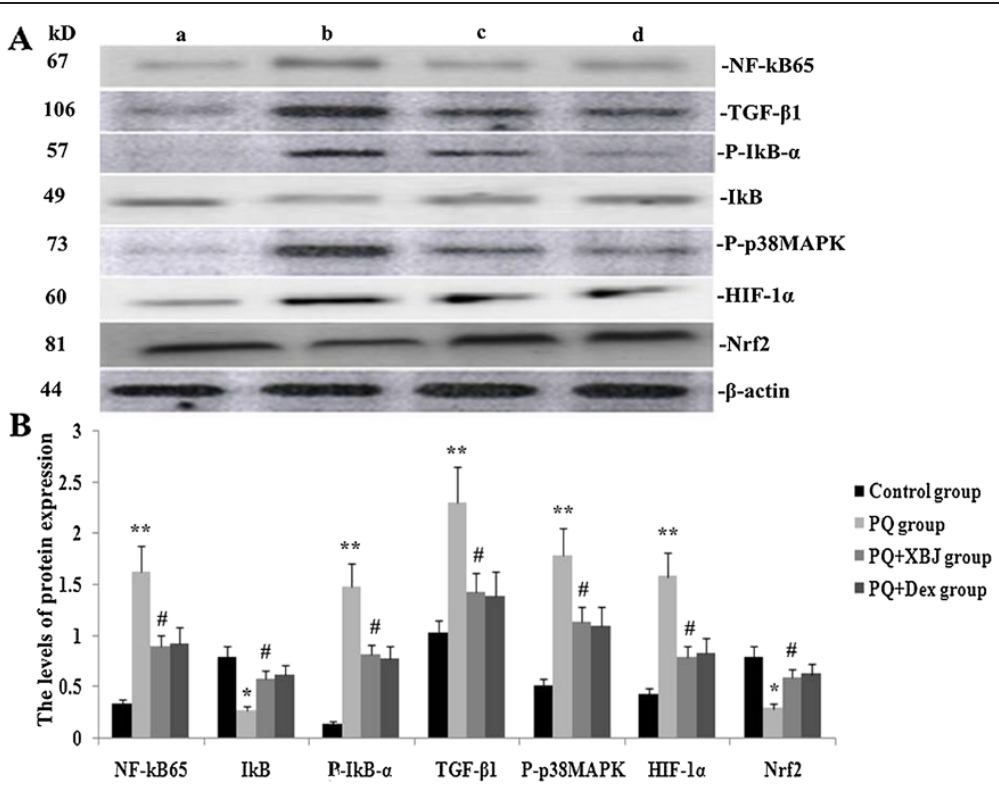

Figure 3 Comparison of expression levels of p-p38 MAPK, NF-KB65, p-ІкB- $a$, IkB, HIF-1a, Nrf2 and TGF- $\beta 1$ using western blotting. A: Representative graphs of protein expression of p-p38 MAPK, NF-kB65, p-|kB-a, IkB, HIF-1a, Nrf2 and TGF- $\beta 1$ (a: control group, b: paraquat group, c: Xuebijing + paraquat group, d: dexamethasone + paraquat group). B: statistical analysis of protein expression of p-p38 MAPK, NF-kB65, p-IkB-a, IkB, HIF-1a, Nrf2 and TGF- $\beta 1$. Data are expressed as mean \pm SEM. ${ }^{*} P<0.01$ compared with control group; ${ }^{*} P<0.05$ compared with paraquat group; $P>0.05$ Xuebijing + paraquat group compared with dexamethasone + paraquat group.

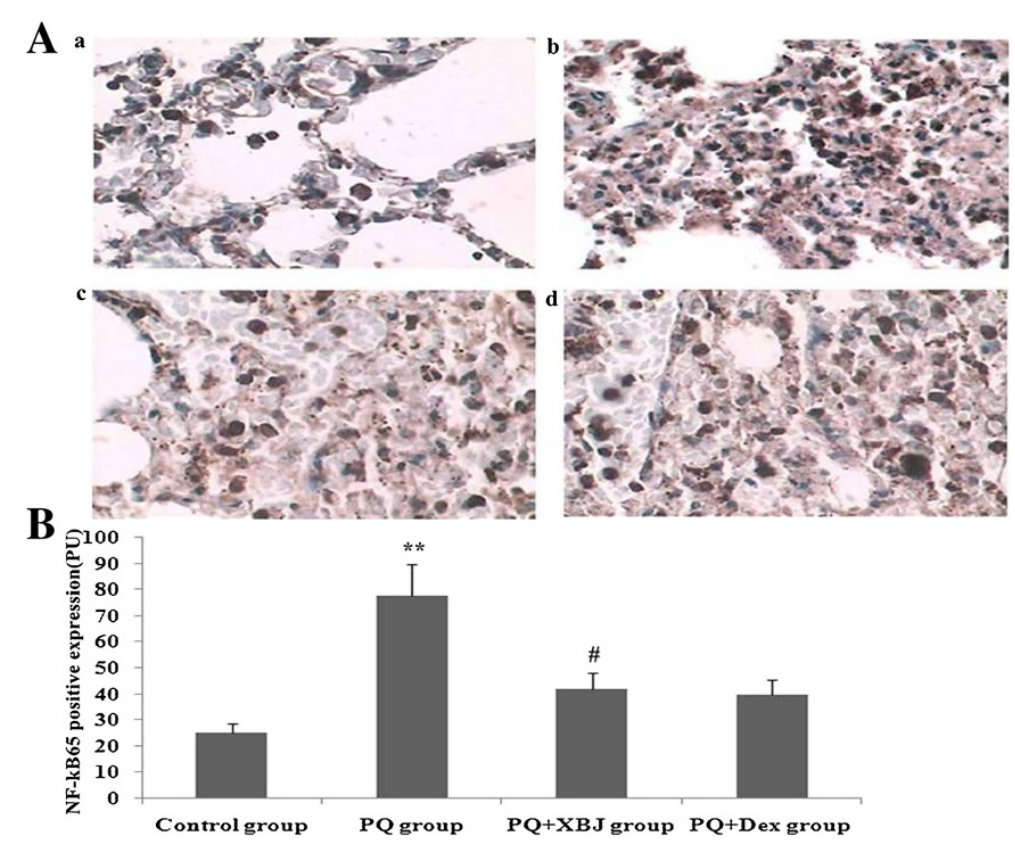

Figure 4 Effect of Xuebijing on the activation of NF-KB65 in paraquat-induced lung tissue using immunohistochemical staining $(\times 200)$. A: Representative immunohistochemical-stained graphs of NF-kB65-positive expression (a: control group, b: paraquat group, c: Xuebijing + paraquat group, d: dexamethasone + paraquat group). B: Statistical analysis of NF-kB65-positive expression. Data are expressed as mean \pm SEM. ${ }^{* *} P<0.05$ compared with control group; ${ }^{\#} P<0.05$ compared with paraquat group; $P>0.05$ Xuebijing + paraquat group compared with dexamethasone + paraquat group. 
in these three pro-inflammatory cytokines at $48 \mathrm{~h}$, and compared with the dexamethasone + paraquat group, there were no significant differences. Paraquat also increased the serum concentration of the anti-inflammatory cytokine IL-10. This change in IL-10 concentration was not altered by intravenous administration of Xuebijing and dexamethasone.

\section{Xuebijing treatment prevented inflammatory cell infiltration in the lungs}

To investigate the potential mechanism underlying the protective effect of Xuebijing on paraquat-induced ALI, we detected the total number of cells, neutrophils, macrophages, lymphocytes and monocytes in BALF from rats treated with paraquat with or without Xuebijing. As shown the Figure 6, paraquat caused a significant increase in inflammatory cell counts in BALF at $48 \mathrm{~h}$. These increases were reduced in the Xuebijing + paraquat group, and compared with the dexamethasone + paraquat group, there were no significant differences.

\section{Xuebijing treatment ameliorated oxidative stress}

To assay the effect of Xuebijing treatment on oxidative stress, ROS, glutathione and oxidised glutathione activities were determined. As shown in Figure 7, ROS and oxidised glutathione activities were significantly higher, and glutathione activity was markedly lower, at $48 \mathrm{~h}$ after paraquat administration. Xuebijing treatment significantly attenuated ROS and oxidised glutathione activities and elevated glutathione activity, and compared with the dexamethasone + paraquat group, there were no significant differences.

\section{Xuebijing treatment reduced the wet/dry weight ratio and BALF protein concentration}

The lung wet-dry weight ratio was significantly higher at $48 \mathrm{~h}$ after paraquat administration. Xuebijing treatment significantly attenuated this change (Figure 4A). Additionally, with regard to endothelial and epithelial permeability, the BALF protein concentration quickly increased after paraquat injection. The paraquat + Xuebijing group also exhibited significantly lower protein concentrations, and compared with the dexamethasone + paraquat group, there were no significant differences (Figure 8).

\section{Xuebijing treatment reduced TGF- $\beta 1$ and PIIIP expression} Concentrations of serum TGF- $\beta 1$ and PIIIP were markedly increased at $48 \mathrm{~h}$ after paraquat administration in the paraquat group and Xuebijing + paraquat group; however, the increase in TGF- $\beta 1$ and PIIIP were suppressed by Xuebijing in paraquat-induced rats, and compared with the dexamethasone + paraquat group, there were no significant differences (Figure 9).

\section{Discussion}

Intentional oral ingestion of even small amounts of paraquat can cause severe and irreversible systemic damage refractory to any known treatment [5]. Upon ingestion, paraquat is rapidly distributed to most organs in the body, but the highest concentrations are found in the kidneys and lungs [7]. Paraquat accumulation in the lungs is facilitated by type I and II alveolar epithelial cells via the polyamine uptake pathway. Subsequent redox cycling and free radical generation initiate a neutrophil-mediated inflammatory response in the lungs [10].

In the current study, paraquat was found to stimulate the infiltration of inflammatory cells into the interstitial and alveolar spaces, and to increase the generation of pro-inflammatory mediators, such as IL- 6 , TNF- $\alpha$ and IL-1 $\beta 1$. Pathological findings demonstrated disrupted alveolar epithelial cells, haemorrhage, oedema, and infiltration of inflammatory cells into lung tissue. Treatment with Xuebijing suppressed the infiltration of inflammatory cells into the interstitial and alveolar spaces, reduced increases in the generation of pro-inflammatory mediators, and extenuated lung injury.

Glucocorticoids, such as dexamethasone, are potent anti-inflammatory drugs frequently prescribed for the

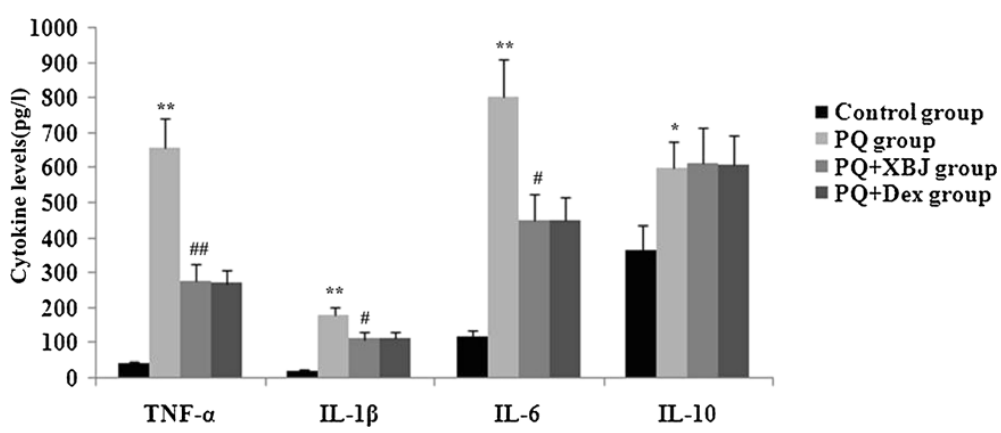

Figure 5 Xuebijing treatment suppressed the production of inflammatory mediators. The levels of TNF- $\alpha$, IL-1 $\beta$, IL-6, and IL-10 in serum were determined using ELISA. Data are expressed as mean \pm SEM. ${ }^{* *} P<0.01$ compared with control group; ${ }^{\#} P<0.05$ and ${ }^{\# \#} P<0.01$ compared with paraquat group; $P>0.05$ Xuebijing + paraquat group compared with dexamethasone + paraquat group. 


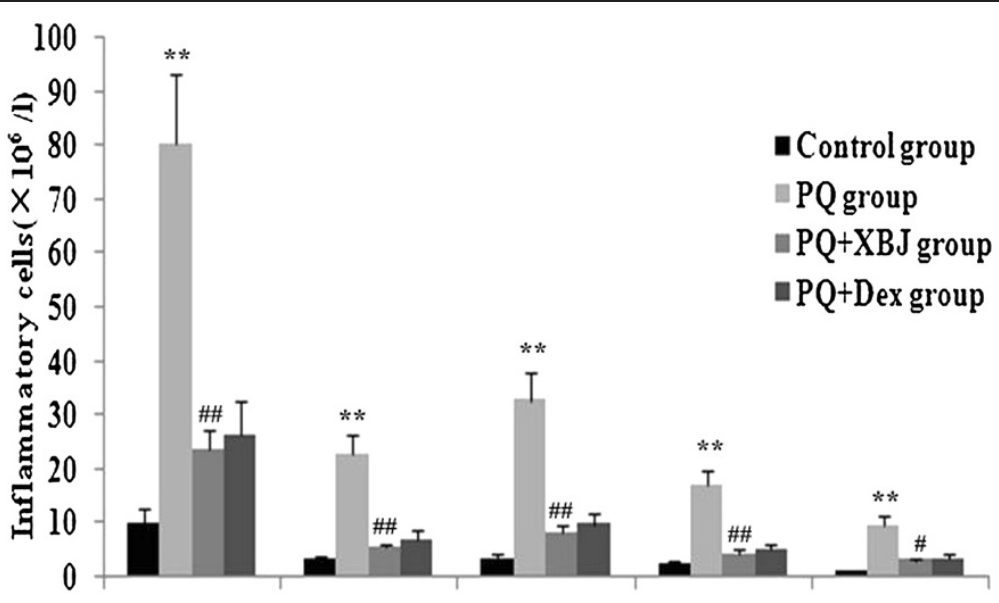

Total cells Macrophages Neutrophils Lymphocytes Monocytes

Figure 6 Xuebijing treatment prevented inflammatory cell infiltration in paraquat-induced lung injury. Inflammatory cells in BALF were measured. Data are expressed as mean \pm SEM. ${ }^{* *} P<0.01$ compared with control group; ${ }^{\#} P<0.05$ and ${ }^{\# \#} P<0.01$ compared with paraquat group; $P>0.05$ Xuebijing + paraquat group compared with dexamethasone + paraquat group.

treatment of various inflammatory diseases, including asthma, chronic obstructive pulmonary disease, and acute respiratory distress syndrome [22]. In addition to these chronic inflammatory diseases, glucocorticoids have also been used for the treatment of severe sepsis and septic shock in patients in the intensive care unit [23]. Clinical trials have indicated that low dose glucocorticoids alleviate the systemic inflammatory response, reduce the duration of shock, and favourably affect survival in patients with septic shock [22]. In animal models of endotoxic shock, prophylactic treatment with dexamethasone attenuates the production of inflammatory cytokines including TNF- $\alpha$ and IL-1 $\beta$, and prevents shock and mortality [24]. Previous studies using prolonged administration of corticosteroids, such as methylprednisolone or dexamethasone, initiated before or simultaneously with bleomycin reduced pulmonary inflammation, lung injury, and collagen deposition in this model [25-27].

Building on this previous research, and to investigate Xuebijing's clinical effects, we established a dexamethasone group as a positive control group. We found that

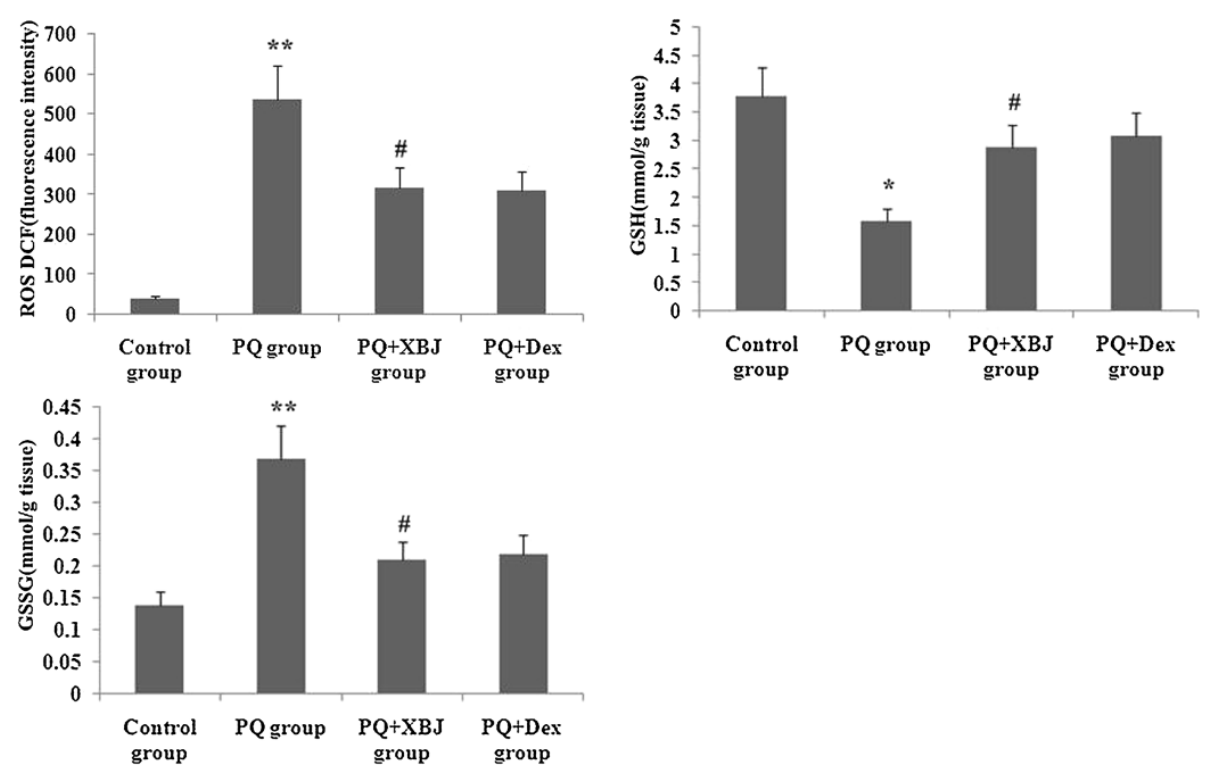

Figure 7 Effect of Xuebijing treatment on ROS, glutathione and oxidised glutathione activities. ROS, glutathione and oxidised glutathione activities were determined. Data are expressed as mean \pm SEM. ${ }^{*} P<0.01$ compared with control group; ${ }^{*} P<0.05$ compared with paraquat group; $P>0.05$ Xuebijing + paraquat group compared with dexamethasone + paraquat group. 

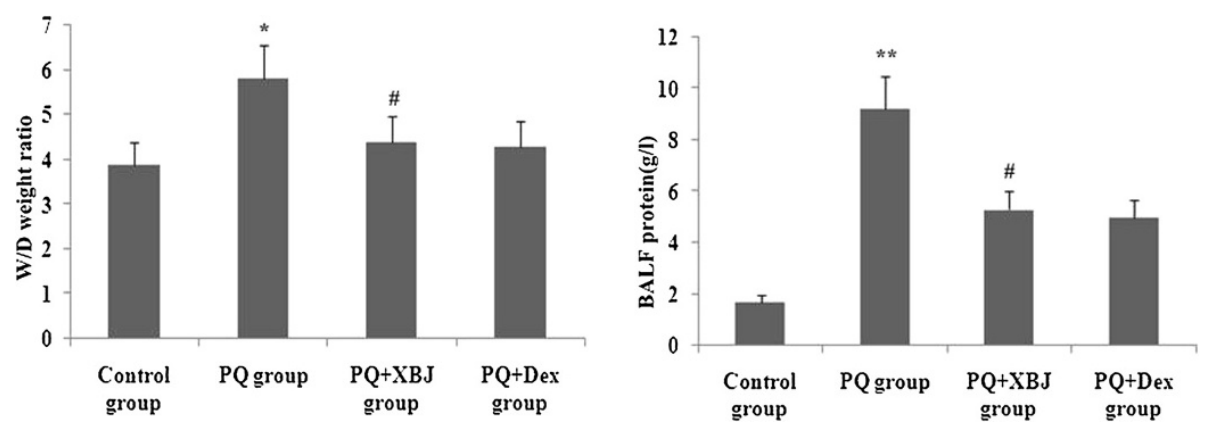

Figure 8 Effects of Xuebijing treatment on the wet/dry weight ratio and BALF protein. Data are expressed as mean \pm SEM. ${ }^{*} P<0.05$; ${ }^{* *} P<0.01$ compared with control group; ${ }^{\#} P<0.05$ and ${ }^{\# \#} P<0.01$ compared with paraquat group; $P>0.05$ Xuebijing + paraquat group compared with dexamethasone + paraquat group.

dexamethasone was as effective as Xuebijing at blocking lung p-p38 MAPK, NF-кB65, HIF- $1 \alpha$, p-ІкB- $\alpha$ and TGF$\beta 1$ expression, increasing Nrf2 expression, inhibiting the inflammatory response and oxidative stress, and extenuating paraquat-induced lung injury.

The present study investigated the effect of Xuebijing on paraquat-induced extra-pulmonary ALI. The experimental model was previously validated as a model of ALI [28], and there is evidence that the metabolic processes, immuno-inflammatory features and histological lung damage in acute paraquat intoxication are similar in humans and rats $[29,30]$. The dose of paraquat used (30 mg/kg of body weight. i.p.) may be classified as moderate exposure to paraquat (60\% of the LD50) in rats $(\mathrm{LD} 50=50 \mathrm{mg} / \mathrm{kg})$ and high exposure in humans, considering a human LD50 of $35 \mathrm{mg} / \mathrm{kg}$ [31]. This dose was sufficient to induce an inflammatory response with increased cell migration and resulted in lung injury, as demonstrated by lung oedema, haemorrhage, alveolar obstruction and collapse. Results from the study showed that Xuebijing treatment markedly inhibited the secretion of inflammatory mediators, reduced cell migration, attenuated lung oedema, haemorrhage, alveolar obstruction and collapse.

The inflammatory reaction plays an important role in ALI in patients following paraquat poisoning, with the release of pro-inflammatory factors resulting in systemic inflammatory response syndrome, as well as the release of anti-inflammatory factors [4]. Clinically, the expression of inflammatory cytokines in the blood is significantly elevated in patients with paraquat poisoning [14].

A limited number of transcription factors regulate the inflammatory pathways, of which the most important transcriptional regulator is NF- $\mathrm{kB}$ [32]. Following activation by a wide array of mediators, including cytokines, bacterial toxins, or oxidative stress, the signal transduction cascade is initiated, and activated NF- $\mathrm{KB}$ can translocate to the nucleus and bind to the promoters of proinflammatory genes, leading to enhanced gene expression and amplification of the inflammatory response. ІкB- $\alpha$ (nuclear factor of kappa light polypeptide gene enhancer in B-cells inhibitor, alpha) is one member of a family of
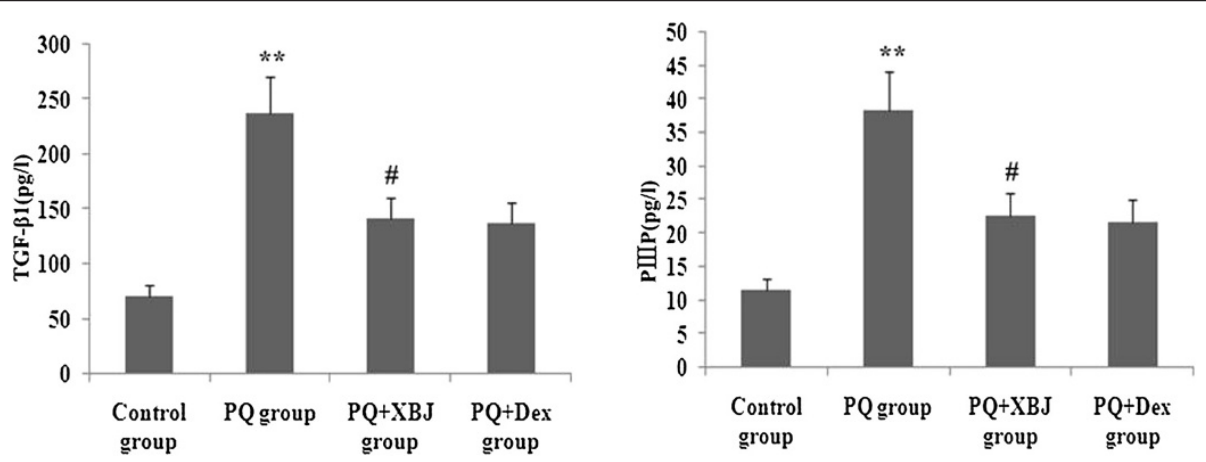

Figure 9 Xuebijing treatment inhibited the generation of TGF- $\beta 1$ and PIIIP. Levels of TGF- $\beta 1$ and PIIIP in serum were determined using ELISA. Data are expressed as mean \pm SEM. ${ }^{*} P<0.01$ compared with control group; ${ }^{\#} P<0.05$ and ${ }^{\# \#} P<0.01$ compared with paraquat group; $P>0.05$ Xuebijing + paraquat group compared with dexamethasone + paraquat group. 
cellular proteins that function to inhibit NF- $\mathrm{kB}$ transcription factor. I $\mathrm{B}-\alpha$ inhibits NF- $\kappa \mathrm{B}$ by masking the nuclear localisation signals of NF- $\mathrm{KB}$ proteins and keeping them sequestered in an inactive state in the cytoplasm [33]. In addition, I $\mathrm{B}-\alpha$ blocks the ability of NF- $\mathrm{B}$ transcription factor to bind to DNA, which is required for NF-kB's proper functioning [34]. As the expression of these proinflammatory mediators is modulated by NF- $\mathrm{kB}$, blocking NF- $\kappa \mathrm{B}$ transcriptional activity may be an important target for treating inflammatory diseases.

Paraquat stimulation elicits a cascade which increases $\mathrm{p}-\mathrm{I} \kappa \mathrm{B}-\alpha$ expression and reduces $\mathrm{IkB}$ expression, resulted in the activation of NF- $\mathrm{kB}$ and the enhanced secretion of pro-inflammatory mediators, which results in lung injury.

The MAPK signalling pathway in macrophages is one of the most extensively investigated intracellular signalling cascades involved in lipopolysaccharide-induced pro-inflammatory responses [35], which are classified into at least three components: extracellular signalregulated kinases $1 / 2$, c-Jun $\mathrm{N}$-terminal kinase, and p38 MAPK, and which have been implicated in the release of immune-related cytotoxic factors and pro-inflammatory cytokines [35]. p38 MAPK is a key mediator of cellular stressors such as inflammation and apoptosis. Both in vitro and in vivo studies have shown that p38 MAPK regulates the production of pro-inflammatory cytokines IL- 6 and TNF- $\alpha$ by increasing cytokine release or messenger RNA transcription [36]. Earlier reports revealed that inhibitors of p38 MAPK (SB203580) reduce lipopolysaccharide-induced pro-inflammatory protein levels [37]. Numerous basic and clinical studies have demonstrated that overexpression of TNF- $\alpha$ and IL-1ß can induce lung injury and that cytokine production is associated with activation of the p38 MAPK pathway [35-38]. Results from our study indicate that paraquat increased p-p38 MAPK expression and further stimulated expression of TNF- $\alpha$ and IL-1ß. However, the increase in p-p38 MAPK expression was inhibited by Xuebijing which inhibited the expression of TNF- $\alpha$ and IL-1ß.

Several lines of evidence suggest that MAPK can participate in the activation of NF- $\mathrm{kB}$ in the cytoplasm as well as in the modulation of its transactivation potential in the nucleus. As the expression of these proinflammatory mediators is modulated by NF- $\mathrm{BB}$, blocking NF- $\mathrm{kB}$ transcriptional activity may be an important target for treating inflammatory diseases. Our findings suggest that the inhibition of MAPK pathways by Xuebijing may be a major mechanism underlying the attenuation of paraquat-induced NF- $\mathrm{kB}$ transcriptional activity.

Oxidative stress is a sign of inflammation. Previous studies on various lung inflammation diseases have confirmed that oxidative stress and oxidative damage are closely related to the development and severity of ALI/ acute respiratory distress syndrome [39]. An imbalance between ROS and the antioxidant defence system results in oxidative stress, which is closely linked to the pathogenesis of acute and chronic lung injury [39]. Increased levels of ROS can cause direct tissue injury and promote inflammatory responses via the regulation of diverse pro-inflammatory mediators in the lungs. The response of a cell to excessive ROS involves the activation of multiple signalling pathways, which can cause transcriptional changes and, consequently, exhibit a variety of activities $[40,41]$. NF- $\mathrm{kB}$ is one of the major transcription factors activated in the lung during oxidative stress, leading to an up-regulation of numerous pro-inflammatory genes, such as T-helper 2 cytokines, which can affect lung injury [42-44]. ROS also attenuates the transcriptional activity of nuclear factor E2-related factor 2 (Nrf2) and stimulates hypoxia-inducible factor (HIF)- $1 \alpha$ expression, resulting in a greater expression of their target genes [45-47]. Some studies have also indicated that ROS functions as a signalling molecule and can stimulate HIF- $1 \alpha$ protein synthesis via the activation of the PI3K/AKT and p42/p44 MAPK pathways. Furthermore, ROS may also have the potential to interfere with prolyl hydroxylase activity to regulate HIF- $1 \alpha$ expression. Glutathione synthesised from cysteine is a vital protective antioxidant against oxidative stress. Our research found that paraquat downregulated Nrf2 expression via increasing NF-kB, HIF-1 $\alpha$ and MAPK activity, increased ROS activity, and inhibited glutathione activity. Expectedly, Xuebijing treatment upregulated $\mathrm{Nrf} 2$ expression via the reduction of the increase in NF- $\mathrm{kB}, \mathrm{HIF}-1 \alpha$ and MAPK activity, markedly enhanced glutathione activity, and improved paraquat-induced lung injury.

TGF- $\beta 1$ is known to enhance the fibrotic process by enhancing fibroblast growth and collagen production as well as promoting the differentiation of fibroblasts into myofibroblasts, which secrete collagen and other extracellular matrix components [48]. In addition, TGF- $\beta 1$ can affect several signal transduction pathways in a Smad-independent manner, such as MAPK, including extracellular signal-related protein kinase, p38 MAPK, and c-Jun N-terminal kinase [49].We also examined TGF- $\beta 1$ expression in the present paraquat-induced mouse model. Consistent with these previous findings, our results showed that expression of TGF- $\beta 1$ and p-p38 MAPK increased after paraquat challenge, and administration of Xuebijing in paraquat-induced rats decreased the increased expression of TGF- $\beta 1$ by blocking the $\mathrm{p} 38$ MAPK pathway.

PIIIP is a crucial component of type III collagen synthesis and is the major collagenous factor in fibrosis [50]. Current perspectives suggest that the increased synthesis of collagen type I, III, and V may play an important role in the pathophysiological mechanism, resulting in intestinal 
fibrosis [51]. Furthermore, the increased synthesis of collagen, namely, an increase in procollagen type III, has been well documented in fibrotic processes involving other organs, such as the liver, pancreas and lung [52]. In this study, we found that paraquat significantly enhanced type III collagen synthesis. However, Xuebijing markedly reduced the production of PIIIP by inhibiting TGF- $\beta 1$ and p38 MAPK expression.

Vascular leakage in multiple organs is a characteristic pathological change in paraquat-induced lung injury [53]. In the present study, we evaluated the wet/dry ratio of the lung and found that Xuebijing treatment attenuated the development of pulmonary oedema, as determined by the significant decrease in lung wet/dry ratio.

As another index of ALI caused by paraquat administration, we measured the total protein concentration in BALF, which indicates epithelial permeability and pulmonary oedema [54]. As expected, paraquat treatment was found to cause a significant increase in BALF protein concentration. Paraquat-induced increases in total protein in BALF were inhibited by Xuebijing through regulating the p38 MAPK pathway.

Xuebijing is a plant-derived Traditional Chinese Medicine that has been successfully applied to treat inflammationassociated diseases, such as sepsis and severe pneumonia [16]. Some studies have revealed its specific effects on various immunomodulatory factors and processes. Xuebijing treatment of peripheral blood mononuclear cells stimulated by exposure to purified bacterial endotoxin lipopolysaccharide has resulted in decreases in tissue factor and protease-activated receptor expression [17]. Severe pneumonia patients treated with Xuebijing have shown decreased secretion of TNF- $\alpha$, IL-6 and IL-8 [55], similarly to patients with sepsis. In addition, Xuebijing treatment, which has been clinically administered, is an intravenous preparation consisting of 32 traditional Chinese medicines. The principal components include Flos Carthami, Radix Paeoniae Rubra, Rhizoma Chuanxiong, Radix Salviae miltiorrhizae [56], Radix Angelica sinensis and Herba houttuyniae. Intravenous Xuebijing treatment is widely used

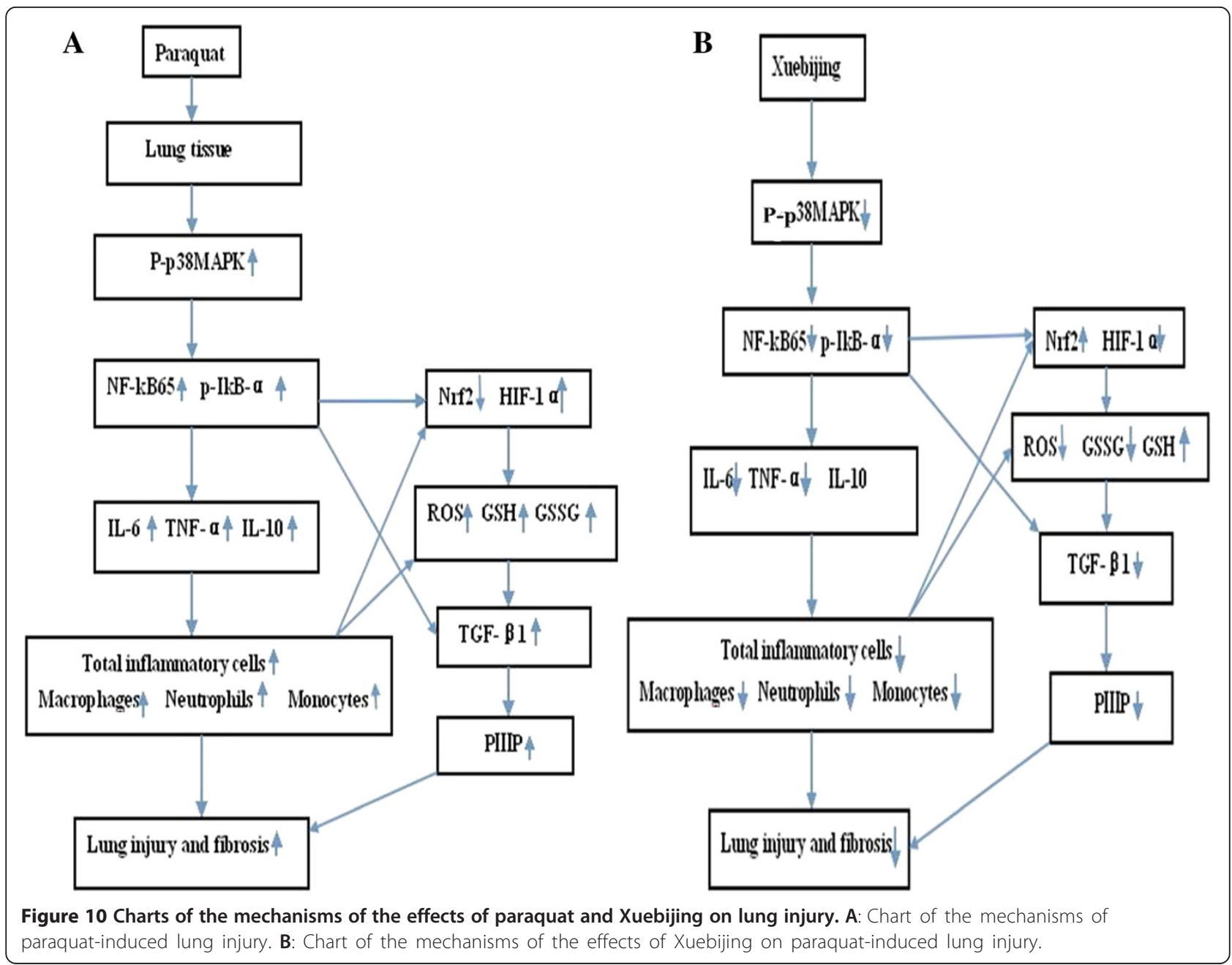


throughout China and has shown clinical success in the treatment of systemic inflammatory response syndrome and multiple organ dysfunction syndrome [56]. The active ingredients of the preparation were recently determined using mass spectrophotometry and included safflor yellow A, ligustrazine, tanshinol, ferulaic acid, and peoniflorin. Ferulaic acid has been previously described for its ability to eliminate oxygen free radicals and to prevent pulmonary fibrosis $[17,18]$.

This study confirmed that treatment with Xuebijing reduced the expression of p38 MAPK and stimulated a reduction in NF-kB65 activity. These findings were evident in the paraquat + Xuebijing group. In addition, reducing the levels of IL-6, IL-1 $\beta$ and TNF- $\alpha$ attenuated the morphological lesions of lung parenchyma; however, the best results were observed in the paraquat + Xuebijing group. In this group, lung oedema was reduced, and there was a slight thickening of the alveolar septum, reduction in inflammatory cell migration and a greater area of free alveolar surface compared with the paraquat groups.

\section{Conclusions}

This study demonstrated that Xuebijing treatment reduced paraquat-induced extra pulmonary ALI in Sprague Dawley rats. The results indicate the effect of its inhibitory activities on p38 MAPK and NF- $k B 65$, the secretion of pro-inflammatory mediators, oxidative stress response, the attenuation of lung permeability leakage and the reduction of morphological damage in lung parenchyma (Figure 10). Further pharmacological evaluations are essential to elucidate the detailed mechanism of the activity of Xuebijing, which may provide insight on its potential to prevent and treat extrapulmonary ALI.

\section{Abbreviations}

ALI: Acute lung injury; TNF-a: Tumour necrosis factor-alpha; IL-6: Interleukin-6; TGF- $\beta$ : transforming growth factor- $\beta$; MAPK: mitogen-activated protein kinase; Nrf2: E2-related factor 2; HIF-1a: Hypoxia-inducible factor-1a; NF-kB: Nuclear factor-kB; PIIIP: Collagen III; ROS: Reactive oxygen species; BALF: Bronchoalveolar lavage fluid.

\section{Competing interests}

The authors declare that they have no competing interests.

\section{Authors' contributions}

LM, CM and SM conceived and designed the experiments. LM, ZW, WY and QC performed the experiments. LM and WL analysed the data. LM, ZW and QC contributed reagents/materials/analysis tools. LM wrote the paper. All authors contributed to and have read and approved the final manuscript.

\section{Acknowledgments}

The authors are grateful for the excellent technical assistance provided by Prof. Lan-fang Qin and Xu Liu.

\section{Funding}

The study received a research grant in 2010 from the Yunnan Science and Technology Agency (No. 2010C093).

\section{Author details}

'Department of Emergency, The First Hospital Affiliated To Kunming Medical University, 295 Xichang Road, Wu Hua District, Kunming 650032, China.
${ }^{2}$ Intensive Care Unit, The Second Hospital Affiliated To Kunming Medical University, 1 Mayuan, Wu Hua District, Kunming 650106, China. ${ }^{3}$ Department of Anesthesiology, The First Hospital Affiliated To Kunming Medical University, 295 Xichang Road, Wu Hua District, Kunming 650032, China. ${ }^{4}$ Department of Respiratory Medicine, The Yan-an Hospital Affiliated To Kunming Medical University, 245 Renmin Eastern Road, Pan Long District, Kunming 650051, China.

Received: 7 December 2013 Accepted: 10 December 2014 Published: 16 December 2014

\section{References}

1. DU Y, Mou Y: Predictive value of 3 methods in severity evaluation and prognosis of acute paraquat poisoning. Zhong Nan Da Xue Bao Yi Xue Ban 2013, 8:737-742. Chinese.

2. Choi JS, Jou SS, Oh MH, Kim YH, Park MJ, Gil HW, Song HY, Hong SY: The dose of cyclophosphamide for treating paraquat-induced rat lung injury. Korean J Intern Med 2013, 28:420-427.

3. Yin Y, Guo X, Zhang SL, Sun CY: Analysis of Paraquat Intoxication Epidemic (2002-2011) within China. Biomed Environ Sci 2013, 26:509-512.

4. Amirshahrokhi K: Anti-inflammatory effect of thalidomide in paraquatinduced pulmonary injury in mice. Int Immunopharmacol 2013, 17:210-215

5. Tian ZG, Ji Y, Yan WJ, Xu CY, Kong QY, Han F, Zhao Y, Pang QF: Methylene blue protects against paraquat-induced acute lung injury in rats. Int Immunopharmacol 2013, 17:309-313.

6. Chen J, Zeng T, Bi Y, Zhong Z, Xie K, Zhao X: Docosahexaenoic acid (DHA) attenuated paraquat induced lung damage in mice. Inhal Toxicol 2013, 25:9-16

7. Tomita M, Okuyama T, Katsuyama H, Miura Y, Nishimura Y, Hidaka K, Otsuki T, Ishikawa T: Mouse model of paraquat-poisoned lungs and its gene expression profile. Toxicology 2007, 231:200-209.

8. Lin $\mathrm{LL}$, Lin-Tan DT, Chen KH, Huang WH: Repeated pulse of methylprednisolone and cyclophosphamide with continuous dexamethasone therapy for patients with severe paraquat poisoning. Crit Care Med 2006, 34:368-373.

9. Zhang LY, Li M, Tao CJ, Ye JM: The Situation of paraquat poisoning and management suggestions. Pesticide Sciand Admin 2011, 32:10-13.

10. Liu Y, Liu Z: Analysis of prognostic factor after paraqua poisoning. Chin $J$ Crit Care Med 2005, 25:679-681

11. Eddleston M, Wilks MF, Buckley NA: Prospects for treatment of paraquatinduced lung fibrosis with immunosuppressive drugs and the need for better prediction of outcome: a systematic review. QJM 2003, 96:809-824

12. Licker M, Schweizer A, Hohn L, Morel DR, Spiliopoulos A: Single lung transplantation for adult respiratory distresssyndrome after paraquat poisoning. Thorax 1998, 53:620-621.

13. Laurent GJ, Coker RK, McAnulty RJ: TGF-beta antibodies: a novel treatment for pulmonary fibrosis? Thorax 1993, 48:953-954.

14. He Q, Chen HX, Li W, Wu Y, Chen SJ, Yue Q, Xiao M, Li JW: IL-36 cytokine expression and its relationship with $\mathrm{p} 38$ MAPK and NF-KB pathways in psoriasis vulgaris skin lesions. J Hua Zhong Univ Sci Technolog Med Sci 2013, 33:594-599.

15. Wang HW, Wu T, Qi JY, Wang YQ, Luo XP, Ning Q: Salidroside attenuates LPS-stimulated activation of THP-1 cell-derived macrophages through down-regulation of MAPK/NF-kB signaling pathways. J Huazhong Univ Sci Technolog Med Sci 2013, 33:463-469.

16. Chen Y, Tong H, Zhang X, Tang L, Pan Z, Liu Z, Duan P, Su L: Xuebijing injection alleviates liver injury by inhibiting secretory function of Kupffer cells in heat stroke rats. J Tradit Chin Med 2013, 33:243-249.

17. Fang $\mathrm{K}$, Wang $\mathrm{XL}$ : Treatment of multiple organ dysfunction syndrome by Xuebijing Injection: a clinical research. Zhongguo Zhong Xi Yi Jie He Za Zhi 2013, 33:205-207.

18. Jiang $M$, Zhou M, Han Y, Xing L, Zhao H, Dong L, Bai G, Luo G: Identication of NF-KB Inhibitors in Xuebijing injection for sepsis fitreatment based on bioactivity-integrated UPLC-Q/TOF. J Ethnopharmacol 2013, 147:426-433.

19. Noble WH, Obdrzalek J, Kay JC: A new technique for measuring pulmonary edema. J Appl Physiol 1973, 34:508-512.

20. Sakuma T, Hida M, Nambu Y, Osanai K, Toga H, Takahashi K, Ohya N, Inoue $M$, Watanabe Y: Effects of hypoxia on alveolar fluid transport capacity in rat lungs. J Appl Physiol 2001, 91:1766-1774

21. Biswas S, Gupta MK, Chattopadhyay D, Mukhopadhyay CK: Insulin induced activation of hypoxia-inducible factor-1 requires generation of 
reactiveoxygen species by NADPH oxidase. Am J Physiol Heart Circ Physiol 2007, 292:H758-H766.

22. Wang $X$, Nelin LD, Kuhlman JR, Meng X, Welty SE, Liu Y: The role of MAP kinase phosphatase- 1 inthe protective mechanism of dexamethasone against endotoxemia. Life Sci 2008, 83:671-680.

23. Annane D: Glucocorticoids in the treatment of severe sepsis and septic shock. Curr Opin Crit Care 2005, 11:449-453.

24. Wong HR, Cvijanovich NZ, Allen GL, Thomas NJ, Freishtat RJ, Anas N, Meye K, Checchia PA, Weiss SL, Shanley TP, Bigham MT, Banschbach S, Beckman E, Harmon K, Zimmerman JJ: Corticosteroids are associated with repression of adaptive immunity gene programs in pediatric septic shock. Am J Respir Crit Care Med 2014, 189:940-946.

25. Phan SH, Thrall RS, Williams C: Bleomycin-induced pulmonary fibrosis. Effects of steroid on lung collagen metabolism. Am Rev Respir Dis 1981, 124:428-434.

26. Koenig WJ, Cross CE, Hesterberg TW, Last JA: The smoking gun Mechanism of methylprednisolone prevention of bleomycin-induced pulmonary fibrosis. Chest 1983, 83:5S-7S.

27. Grunze MF, Parkinson D, Sulavik SB, Thrall RS: Effect of corticosteroids on lung volume-pressure curves in bleomycin- induced lung injury in the rat. Exp Lung Res 1988, 14:183-195.

28. Sun ML, Ma DH, Liu M, Yu YX, Cao DB, Ma C, Wang X, Liu XL: Successful treatment of paraquat poisoning by Xuebijing, an injection concocted from multiple Chinese medicinal herbs: a case report. $J$ Altern Complement Med 2009, 15:1375-1378.

29. Rocco PRM, Negri EM, Kurtz PM: Vasconcellos FP, Silva GH, Capelozzi VL, Romero $P V$, Zin WA: Lung tissue mechanics and extracellular matrix remodeling in acute lung injury. Am J Respir Crit Care Med 2001, 164:1067-1071.

30. Rocco PR, Souza AB, Faffe DS, Pássaro CP, Santos FB, Negri EM, Lima JG, Contador RS, Capelozzi VL, Zin WA: Effect of corticosteroid on lung parenchyma remodeling at an early phase of acute lung injury. Am J Respir Crit Care Med 2003, 168:677-684.

31. Sittipunt C: Paraquat poisoning. Respir Care 2005, 50:383-385

32. Sun YN, Li W, Yan XT, Yang SY, Song SB, Kim YH: Phenolic components from the stem of Acanthopanax koreanum and their inhibitory effects on NF-kappa B. Biosci Biotechnol Biochem 2014, 78:374-377.

33. Jacobs MD, Harrison SC: Structure of an IkappaBalpha/NF-kappaB complex. Cell 1998, 95:749-758.

34. Verma IM, Stevenson JK, Schwarz EM, Van Antwerp D, Miyamoto S: Rel/NFkappa B/I kappa B family: intimate tales of association and dissociation. Genes Dev 1995, 9:2723-2735.

35. Nadeem A, Siddiqui N, Alharbi NO, Alharbi MM, Imam F: Acute glutathione depletion leads to enhancement of airway reactivity and inflammation via p38MAPK-iNOS pathway in allergic mice. Int Immunopharmacol 2014, 22:222-229.

36. Holen E, Espe M, Andersen SM, Taylor R, Aksnes A, Mengesha Z, Araujo P: A co culture approach show that polyamine turnover is affected during inflammation in Atlantic salmon immune and liver cells and that arginine and LPS exerts opposite effects on p38MAPK signaling. Fish Shellfish Immunol 2014, 37:286-298.

37. Guo R, Wu K, Chen J, Mo L, Hua X, Zheng D, Chen P, Chen G, Xu W, Feng J: Exogenous hydrogen sulfide protects against doxorubicin-induced inflammation and cytotoxicity by inhibiting p38MAPK/NFKB pathway in H9c2 cardiac cells. Cell Physiol Biochem 2013, 32:1668-1680.

38. Lan A, Xu W, Zhang H, Hua X, Zheng D, Guo R, Shen N, Hu F, Feng J, Liu D: Inhibition of ROS-activated p38MAPK pathway is involved in the protective effect of $\mathrm{H} 2 \mathrm{~S}$ against chemical hypoxia-induced inflammation in PC12 cells. Neurochem Res 2013, 38:1454-1466.

39. Tasaka S, Amaya F, Hashimoto S, Ishizaka A: Roles of oxidants and redox signaling in the pathogenesis of acute respiratory distress syndrome. Antioxid Redox Signal 2008, 10:739-753.

40. Roper JM, Mazzatti DJ, Watkins RH, Maniscalco WM, Keng PC, O'Reilly MA: In vivo exposure to hyperoxia induces DNA damage in a population of alveolar type II epithelial cells. Am J Physiol Lung Cell Mol Physiol 2004, 286:L1045-L1054.

41. Barazzone C, Horowitz S, Donati YR, Rodriguez I, Piguet PF: Oxygen toxicity in mouse lung: pathways to cell death. Am J Respir Cell Mol Biol 1998, 19:573-581.

42. Lee YC, Lee KS, Park SJ, Park HS, Lim JS, Park KH, Im MJ, Choi IW, Lee HK, Kim UH: Blockade of airway hyperresponsiveness and inflammation in a murine model of asthma by a prodrug of cysteine, L-2-oxothiazolidine-4carboxylic acid. FASEB J 2004, 18:1917-1919.

43. Tanabe T, Fujimoto K, Yasuo M, Tsushima K, Yoshida K, Ise H, Yamaya M: Modulation of mucus production by interleukin-13 receptor alpha2 in the human airway epithelium. Clin Exp Allergy 2008, 38:122-134.

44. Yasuo M, Fujimoto K, Tanabe T, Yaegashi H, Tsushima K, Takasuna K, Koike T, Yamaya M, Nikaido T: Relationship between calcium-activated chloride channel 1 and MUC5AC in goblet cell hyperplasia induced by interleukin-13 in human bronchial epithelial cells. Respiration 2006 73:347-359

45. Cheng SE, Lee IT, Lin CC, Kou YR, Yang CM: Cigarette smoke particle-phase extract induces $\mathrm{HO}-1$ expression in human tracheal smooth muscle cells: Role of the c-Src/NADPH oxidase/MAPK/Nrf2 signaling pathway. Free Radic Biol Med 2010, 48:1410-1422.

46. Papaiahgari S, Zhang Q, Kleeberger SR, Cho HY, Reddy SP: Hyperoxia stimulates an Nrf2-ARE transcriptional response via ROS-EGFR-PI3K-Akt/ ERK MAP kinase signaling in pulmonary epithelial cells. Antioxid Redox Signal 2006, 8:43-52

47. Koshikawa N, Hayashi J, Nakagawara A, Takenaga K: Reactive oxygen species-generating mitochondrial DNA mutation up-regulates hypoxiainducible factor-1alpha gene transcription via phosphatidylinositol 3-kinase-Akt/protein kinase C/histone deacetylase pathway. J Biol Chem 2009, 284:33185-33194.

48. Kotecha S, Wangoo A, Silverman M, Shaw RJ: Increase in the concentration of transforming growth factor beta- 1 in bronchoalveolar lavage fluid before development of chronic lung disease of prematurity. J Pediatr 1996, 128:464-469.

49. Painemal P, Acuña MJ, Riquelme C, Brandan E, Cabello-Verrugio C: Transforming growth factor type beta 1 increases the expression of angiotensin II receptor type 2 by a SMAD- and p38 MAPK-dependent mechanism in skeletal muscle. Biofactors 2013, 39:467-475.

50. Kjeldsen J, de Schaffalitzky Muckadell OB, Junker P: Seromarkers of collagen I and III metabolism in active Crohn's disease. Relation to disease activity and response to therapy. Gut 1995, 37:805-810.

51. Stallmach A, Schuppan D, Riese HH, Matthes H, Riecken EO: Increased collagen type III synthesis by fibroblasts isolated from strictures of patients with Crohn's disease. Gastroenterology 1992, 102:1920-1929.

52. Blois A, Srebro B, Mandalà M, Corti A, Helle KB, Serck-Hanssen G: The chromogranin A peptide vasostatin-l inhibits gap formation and signal transduction mediated by inflammatory agents in cultured bovine pulmonary and coronary arterial endothelial cells. Regul Pept 2006, 135:78-84.

53. Shah D, Romero F, Stafstrom W, Duong M, Summer R: Extracellular ATP mediates the late phase of neutrophil recruitment to the lung in murine models of acute lung injury. Am J Physiol Lung Cell Mol Physiol 2014, 306:L152-L161.

54. Rehberg S, Yamamoto Y, Sousse LE, Jonkam C, Zhu Y, Traber LD, Cox RA, Prough DS, Traber DL, Enkhbaatar P: Antithrombin attenuates vascular leakage via inhibiting neutrophil activation in acute lung injury. Crit Care Med 2013, 41:e439-e446.

55. Li HF, Sun ML, Yu YX, Liu XL: Xuebijing alters tumor necrosis factor-alpha, interleukin-1beta and p38 mitogen activated protein kinase content in a rat model of cardiac arrest following cardiopulmonary resuscitation. Neural Regen Res 2011, 6:2573-2576.

56. Liu QQ, Zhu XQ, Wang L: Effects of Xuebijing injection on survival rats and liver-kidey function in rats with sepsis. JETCM 2008, 17:203-205.

\section{doi:10.1186/1472-6882-14-498}

Cite this article as: Liu et al:: Protective effect of Xuebijing injection on paraquat-induced pulmonary injury via down-regulating the expression of p38 MAPK in rats. BMC Complementary and Alternative Medicine 2014 14:498. 